\title{
LIPASE B DE Candida antarctica IMOBILIZADA EM POLIURETANO: UM BIOCATALISADOR MUITO ESTÁVEL NA PRESENÇA DE PERÓXIDO DE HIDROGÊNIO
}

\author{
N. L. D. NYARI ${ }^{1}$; J. ZENI ${ }^{1}$; I. A. FERNANDES ${ }^{1}$; A. ANTUNES ${ }^{1}$; R. SCHERER ${ }^{1}$; A. M. M. \\ FICANHA $^{1}$; R. M. DALLAGO ${ }^{1}$ \\ ${ }^{1}$ Universidade Regional Integrada do Alto Uruguai e Missões, URI- Erechim, RS, Departamento \\ de Engenharia de Alimentos \\ E-mail: nadialigianara@hotmail.com
}

\begin{abstract}
RESUMO - A lipase de Candida antarctica B (CAL B) está entre as enzimas mais utilizadas em biocatálise, pois possui flexibilidade na sua estrutura e permite a sintonização de suas propriedades. A versatilidade destes biocatalisadores permite o seu uso em uma grande variedade de reações, como estereficação, interesterefição ou hidrólise. A característica comum entre essas aplicações é a necessidade de utilizar a enzima na presença de peróxido de hidrogénio ou um derivado com solubilidade em meios orgânicos. A enzima Novozym 435 (uma preparação imobilizada comercial de lipase CAL B) e a enzima CAL B imobilizada em poliuretano foram submetidas a teste de estabilidade frente a diferentes concentrações de peróxido de hidrogênio (1, 5 e $10 \mathrm{M})$. No decorrer de 80 dias, em temperatura ambiente $\left(10-25{ }^{\circ} \mathrm{C}\right)$, a enzima imobilizada em poliuretano submtida a uma solução de peróxido de hidrogênio na concetração de $1 \mathrm{M}$ apresentou atividade residual de 36,5\% em 30 dias de contato. Quando utilizado a concentração $5 \mathrm{M}$ apresentou $38 \%$ e na concentração de $10 \mathrm{M}$ apresentou $46 \%$ de atividade residual. Enquanto a Novozym 435 apresentou cerca de 15\% de atividade residual após 24 horas. Os resultados demonstraram que a lipase de Candida antarctica $\mathrm{B}$ imobilizada em poliuretano apresentou maior estabilidade frente ao peróxido de hidrogênio quando comparado com a enzima imobilizada comercial Novozym 435, mostrando - se muito mais eficiente e economico.
\end{abstract}

\section{INTRODUÇÃO}

A lipase de Candida antarctica B (CAL B), é a enzima mais utilizadas em biocatálise, sendo um excelente biocatalisador para uma ampla variedade de transformações régio-enantioseletiva através de vários tipos de reações, tais como hidrólise, esterificação e transesterificação (Itabaiana Jr. et al., 2013; Miyazawa et al., 2013).

A sua versatilidade conduz a várias aplicações industriais, principalmente a enantioseletividade que é explorada na formulação de fármacos, resolução dos álcoois racémicos, ácidos, ésteres ou aminas (Gotor Fernández et al., 2006). Destacam-se ainda na substituição de processos sintéticos 


\section{9 a 22 de outubro de 2014 \\ Florianópolis/SC}

industriais: nos produtos farmacêuticos, síntese de ésteres de hidratos de carbono, aminas e amidas, cosméticos, detergentes, couro, na indústria de alimentos (sabor e aroma) entre outros (Huang et al., 2006).

O inconveniente do uso de lipase de Candida antarctica B (CAL B) na sua forma livre como biocatalisador comparado com catálise química é principalmente por possuir estabilidade baixa e alto custo. Consequentemente, existe um crescente interesse no desenvolvimento de biocatalisadores imobilizados para aplicações industriais. A imobilização pode proporcionar uma melhora das propriedades catalíticas tais como: a atividade, a estabilidade, a reutilização, a alta seletividade (reduz as reações colaterais), e a preservação da atividade catalítica ao longo de vários ciclos de reação, aumentando o custo-benefício (Cantone et al., 2012; Hernandez e Fernandez-Lafuente 2011a).

$\mathrm{O}$ peróxido de hidrogênio $\left(\mathrm{H}_{2} \mathrm{O}_{2}\right)$ é um dos oxidantes versátil, superior ao cloro, dióxido de cloro e permanganato de potássio. Pela catálise, o $\mathrm{H}_{2} \mathrm{O}_{2}$ pode ser convertido em radical hidroxila $(\mathrm{OH})$ com reatividade inferior apenas ao flúor. Além de ser um agente oxidante pode também ser empregado como agente. Na sua forma isolada ou combinada, são empregados em diversas aplicações (Hernandez e Fernandez-Lafuente 2011b).

O peróxido de hidrogênio é também importante nas áreas envolvidas com alimentos, medicamentos, monitoramento de processos, dentre outras. Está presente em inúmeras reações biológicas como principal produto de várias oxidases, e é um parâmetro importante na quantificação destes bioprocessos (De Mattos et al., 2003).

Estes compostos fortes são inativantes de enzima, modificam os aminoácidos das proteínas (Arg, Pro, Lys, Met, Cys, Tyr, His) (Hernandez e Fernandez-Lafuente 2011b). No entanto, a lipase CAL B tem sido utilizada em alguns casos por se mantém resistente neste solvente e por possuir alta porcentagem de atividade, mesmo após várias horas de incubação. Torna-se um alvo interessante, considerando as propriedades físicas do peróxido de hidrogénio pode levar à inativação irreversível da enzima ou inibindo a formação do radical e impedindo o início da reação e possível formação de $\mathrm{O}_{2}$ (Tzialla et al ,2010; Churakova et al.,2013).

Entre estas reações, o uso de lipases para a produção de perácidos com diferentes propósitos do correspondente possui ácido ou éster vem atraindo grande interesse. Desta forma, objetivou-se estudar a estabilidade de lipases imobilizadas em poliuretano (PU) na presença de altas concentrações de peróxido de hidrogênio $\left(\mathrm{H}_{2} \mathrm{O}_{2}\right)$ e compará-la com a estabilidade da enzima comercial imobilizada Novozym 435.

\section{MATERIAL E MÉTODOS}

\subsection{Materiais}

A imobilização foi realizada utilizando a lipase de Candida antarctica do tipo B (Novozyme NZL-102, CAL B), lipase comercial 435 Novozym, adquirida na forma liofilizada da empresa

Novozymes Latin América Ltda. A enzima CAL B líquida foi previamente diluída em $\mathrm{H}_{2} \mathrm{O}$, na 


\section{9 a 22 de outubro de 2014 \\ Florianópolis/SC}

proporção 0,16\% (v/v) (enzima:água). Os monômeros comerciais poliol e isocianato foram produzidos com uma formulação específica para colchões e espumas injetadas, pela Empresa Flexível Poliuretanos-Mannes. Os solventes utilizado foram Acetona (FMaia), Ácido Oléico (Vetec), Álcool Etílico (Merck), Hidróxido de Sódio (Nuclear) e Peróxido de Hidrogênio (Merck).

\subsection{Polimerização e Imobilização}

A reação de polimerização para obtenção do poliuretano (PU) foi realizada variando a razão dos monômeros poliol:isocianato (6:4 (v/v)), segundo metodologia de Silva et al., (2013) modificada em relação a concentração dos mesmos.

O procedimento de imobilização da enzima CAL B em PU foi realizada na concentração préestabelecida da etapa anterior, onde $10 \%$ da enzima diluída foi adicionada ao monômero (Poliol) sendo homogeneizado e em seguida adicionado o isocianato. Após a etapa de polimerização, o poliuretano contendo a enzima (imobilizado) foi mantido durante 24 horas em dessecador para equalização do teor de umidade, para posterior medida da atividade por esterificação, comparando a enzima na sua forma livre.

\subsection{Determinação da Atividade de Esterificação}

A atividade de esterificação das foi realizada pela quantificação da reação de síntese do ácido oleico e etanol (razão molar 1:1 (v/v)). A reação foi conduzida a $40{ }^{\circ} \mathrm{C}, 160 \mathrm{rpm}$ por $40 \mathrm{~min}$. Esta foi iniciada pela adição da enzima $(0,1 \mathrm{~g})$ ao meio reacional, em frascos de vidro com tampa, mantidos em agitador orbital. Alíquotas de $500 \mu \mathrm{L}$ foram retiradas do meio reacional em triplicata no início da reação. A cada amostra foram adicionados $15 \mathrm{~mL}$ de uma solução de acetona-etanol (1:1) (v/v) para paralisar a reação e para extração de éster de oleato de etila segundo Paroul et al (2010 e 2011). A quantidade de ácido consumida foi determinada por titulação com $\mathrm{NaOH} \mathrm{0,05} \mathrm{M} \mathrm{até} \mathrm{pH} 11$.

Uma unidade de atividade enzimática foi definida como a quantidade de enzima que consome $1 \mu \mathrm{mol}$ de ácido graxo por minuto, nas condições do ensaio. A atividade enzimática foi calculada baseando em Brígida et al., 2010).

\subsection{Estabilidade da enzima imobilizada em Peróxido de Hidrogênio}

A incubação de amostras diferentes CAL B na presença de peróxido de hidrogénio, foi realizado variando a molaridade das mesmas: $1 \mathrm{M}, 5 \mathrm{M}$ e $10 \mathrm{M}$ em temperatura ambiente, entre 10 e $25{ }^{\circ} \mathrm{C}$, onde as amostras de lipase $(500 \mathrm{mg})$ foram incubadas em $20 \mathrm{~mL}$ de solução de peróxido de hidrogênio. $\mathrm{O}$ pH das soluções não foi ajustado, porém, verificou-se uma variação entre pHs de 3,84,3, dependendo da concentração de peróxido de hidrogénio utilizada. Foram retiradas amostras periodicamente. As amostras foram filtradas e deixadas em estufa a $40{ }^{\circ} \mathrm{C}$ por 30 min para evaporação do solvente. As amostras foram pesadas e realizou-se a medida da atividade de esterificação. Os experimentos foram realizados em triplicata e os resultados são demonstrados como médias da atividade residual (Tzialla et al., 2010; Hernandez e Fernandez-Lafuente 2011b). 


\section{RESULTADOS E DISCUSSÕES}

O derivado CAL B imobilizado em poliuretano (PU) apresentou atividade inicial de 1666,73 U/g (0,16 g de enzima adicionada ao suporte) enquanto a lipase comercial 435 Novozym 435 (preparação comercial da lipase utilizada B de Candida antarctica (CAL B) imobilizada obteve atividade 643,564 U/g. Ambas preparações foram submetidas a estabilidade a diferentes concentrações de peróxido de hidrogénio (1M, 5M e 10M) como demonstrado na Figura 1.

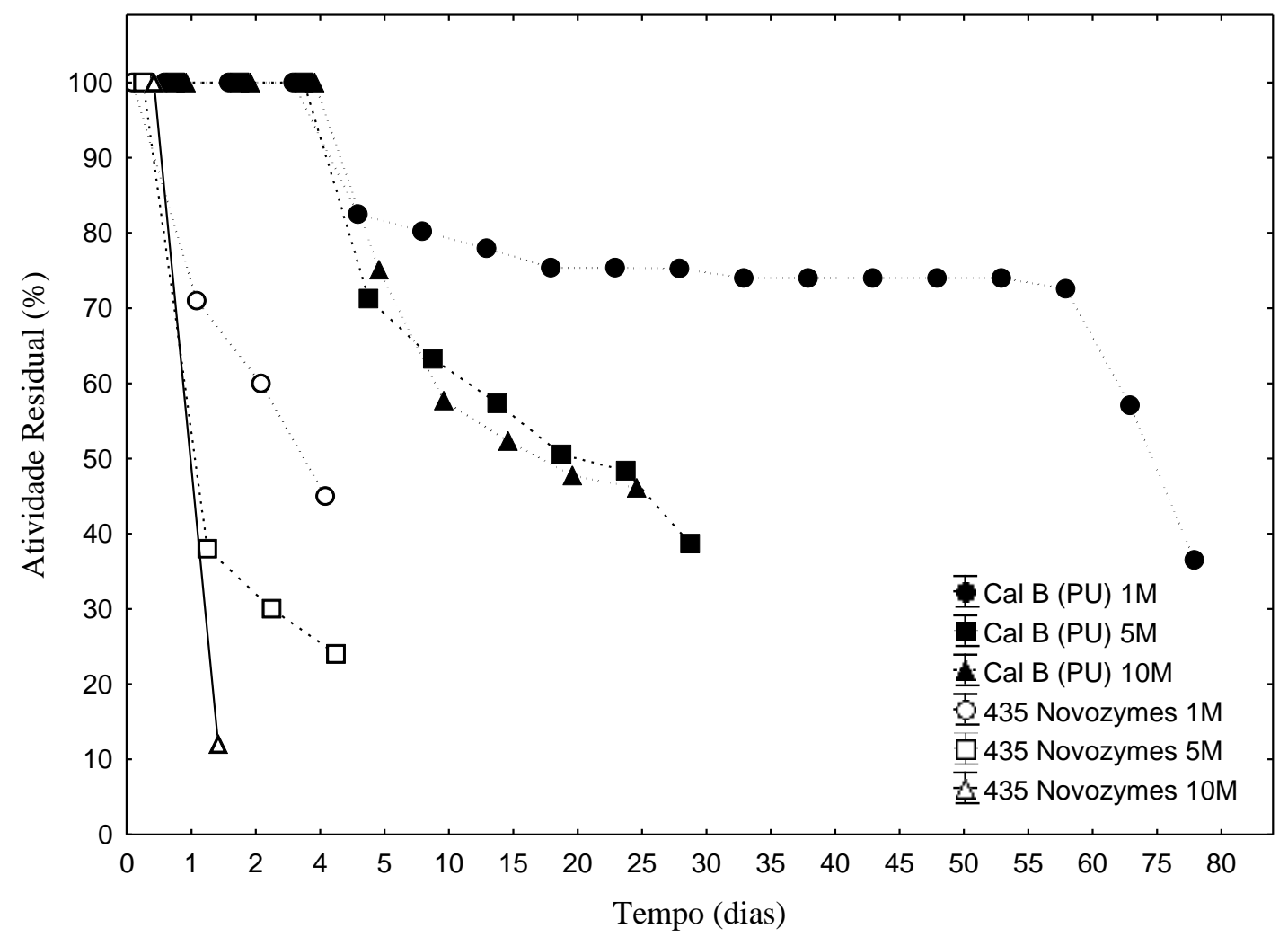

Figura 1 - Inativação em diferente concentraçoes de peróxido de hidrogênio da enzima imobilizada de CAL B em Poliuretano (PU) e Novozyme 435.

O comportamento da enzima na presença dessas elevadas concentrações de peróxido de hidrogênio está de acordo com o relatado na literatura (Tzialla et al., 2010; Hernandez e FernandezLafuente 2011b). No entanto, também é possível detectar diferenças na estabilidade das diferentes biocatalisadores, enquanto CAL B em PU submetido a solução de peróxido de hidrogênio na concentração de $1 \mathrm{M}$ por um período de 80 dias de contato apresentou atividade residual de 36,5\%. Em concentrações maiores, $5 \mathrm{M}$ e $10 \mathrm{M}$, apresentaram atividade residual de $38 \%$ e $46 \%$, respectivamente, em um período de 30 dias.

A Novozym 435 demostrou-se pouco estável na presença de peróxido de hidrogênio na concentração de 1 M (após 4 dias retenção de 55\%) e em 5M obteve 30\% em 24 horas. A utilização 


\section{9 a 22 de outubro de 2014 \\ Florianópolis/SC}

de peróxido de hidrogênio na concentração de $1 \mathrm{M}$, e $5 \mathrm{M}$ apresentaram atividade de $15 \%$ em $24 \mathrm{~h}$, essa taxa pela metade utilizando a concentração de $1 \mathrm{M}$ em $12 \mathrm{~h}$, tendo um efeito muito negativo sobre a estabilidade da enzima (Hernandez e Fernandez-Lafuente 2011b).

Os efeitos negativos do uso de peróxido hidrogênio sobre a enzima CAL B são pouco explicados na literatura de acordo com Rodrigues e Fernandez-Lafuente (2010a e 2010b). O peróxido de hidrogênio pode modificar diretamente alguns grupos (as áreas hidrofóbicas ao redor do centro ativo) ligados diretamente na catálise ou críticos para manter a estrutura da enzima, sendo capaz de penetrar nos poros do suporte entrando em contato com a enzima atacando e modificando-os. A baixa eletrofilicidade do peróxido de hidrogênio, bem como à tendência em formar radicais, é necessário o uso de catalisadores bastante efetivos para que a reação de epoxidação ocorra. A utilização de ácidos fortes como ativadores do peróxido para que este aja com maior eficiência como doador de oxigênio é comum e industrialmente aplicado (Torres et al., 2012).

Estudos realizados utilizando a enzima Novozym 435 em contato com o peróxido de hidrogênio $5 \%$ (w/w) em oito horas de reação apresentou a desativação da enzima. Esses resultados sugerem que este processo não pode ser feito a uma escala industrial. Mais estudos com diferentes modos de operação tem de ser realizados a fim de reduzir a inativação da enzima e transformar a epoxidação quimio-enzimática em um processo economicamente viável (Severiano, 2008).

Torres et al. (2012), utilizaram peróxido de hidrogênio (2 M) e desenvolveram um método muito eficaz para a epoxidação do biodiesel com altos rendimentos e seletividade para a formação de epóxido (> 99\%) e ainda com a possibilidade de reutilização do catalisador por sete ciclos. Hernandez e Roberto Fernandez-Lafuente (2011b) utilizaram a Novozym 435 para a preparação de perácido, ou seja imobilizaram a enzima em Sepabeads octadecilo em suporte hidrofóbicos. Esta preparação manteve $55 \%$ da atividade inicial ao fim de 4 dias de incubação em peróxido de hidrogénio $10 \mathrm{M}$ a 22 ${ }^{\circ} \mathrm{C}$, enquanto Novozym 435 foi mantida por $24 \mathrm{~h}$ e apresentou atividade residual de apenas $15 \%$.

Quando lipase de Rhizomucor miehei foi testada em contato com peróxido de hidrogênio 5 M, foi completamente inativado após $4 \mathrm{~h}$, o que demonstra que esta enzima foi, menos estável do que a CAL B. Além disso, a atividade CAL B perdida pode ser parcialmente recuperada através de incubação da amostra CAL B oxidado com boro-hidreto de sódio (Chung et al., 1998).

Corrêa et al. (2012) utilizou lipase de Burkholderia cepacia imobilizada em cerâmica e mostrou o seu melhor comportamento como biocatalisador para a reação de epoxidação, após 3 horas a $55{ }^{\circ} \mathrm{C}$, $10 \%$ de carga de enzima, $0,2 \%$ de peróxido de hidrogénio e, aplicando-se a $150 \mathrm{rpm}$ como agitação, apresentou rendimento de epóxido era cerca de $88 \%$.

Estes resultados sugerem um efeito benéfico da imobilização sobre a atividade da enzima. Esta tendência pode estar relacionada com varias fatores como, a disponibilização facilidade do acesso de novos sítios ativos, possibilidade da reutilização do biocatalisador imobilizado, facilidade na separação do meio reacional, sem contaminação do produto final pela enzima e melhor controle do processo. 


\section{9 a 22 de outubro de 2014 \\ Florianópolis/SC}

Portanto, muitos dos grupos envolvidos no a interação entre CAL B e o apoio deve ser alvos da modificações, sendo assim, comprova-se que a CAL B em PU possui características atípicas e oferece múltiplas possibilidades de investigar mais os resultados, podendo ser utilizados meios orgânicos na indústria.

\section{CONCLUSÕES}

A lipase de Candida antarctica do tipo B imobilizada em suporte de poliuretano (PU) provou ser um biocatalisador muito adequado, podendo ser empregado em altas concentrações de peróxido de hidrogênio. A enzima manteve níveis elevados de atividade residual por longo período, mesmo após usar concentrações altas $(10 \mathrm{M})$ deste reagente. A enzima imobilizada comercial Novozym 435 apresentou inativação quando testada a estabilidade em concentração de peróxido de hidrogênio a 5 M em um período de 24 horas, o que indica que o peróxido é capaz de penetrar os poros do suporte deste derivado, causando a desnaturação.

\section{REFERÊNCIAS BIBLIOGRÁFICAS}

BRÍGIDA, A. I. S.; CALADO, V. M. A.; GONÇALVES, L. R. B.; COELHO, M. A. Z. Effect of chemical treatments on properties of green coconut fiber. Carbyd. Polym., v. 79, p. 832-838, 2010.

CANTONE, S.; SPIZZO, P.; FATTOR, D.; FERRARIO, V.; EBERT, C.; GARDOSSI, L.; Lipases for bio-based chemistry: Efficient immobilized biocatalysts for competitive biocatalysed processes. Chim. Oggi-Chem. Today., v. 30, p. 10-14, 2012.

CHUNG, L. Y.; SCHMIDT, R. J.; HAMLYN, P. F.; SAGAR, B. F.; ANDREWS, A. M.; TURNER, T. D. Biocompatibility of potential wound management products: Hydrogen peroxide generation by fungal chitin/chitosans and their effects on the proliferation of murine L929 fibroblasts in culture. J. Biom. Mat. Res., v. 39, p. 300-307, 1998.

CHURAKOVA, E.; ARENDS, I. W.; HOLLMANN, F. Increasing the Productivity of Peroxidase Catalyzed Oxyfunctionalization: A Case Study on the Potential of Two Liquid Phase Systems. Chem. Cat. Chem., v. 5, p. 565-568, 2013.

CORRÊAA, F. D. A.; SUTILI, F. K.; MIRANDA, L. S.; LEITE, S. G.; DE SOUZA, R. O.; LEAL, I. C. Epoxidation of oleic acid catalyzed by PSCI-Amano lipase optimized by experimental design. J. Mol. Catal. B: Enzym., v. 81, p. 7-11, 2012.

GOTOR-FERNÁNDEZ, V.; BUSTO, E.; GOTOR, V. Candida antarctica lipase B: an ideal biocatalyst for the preparation of nitrogenated organic compounds. Adv. Synthes. Catal., v. 348, p. 797-812, 2006.

HERNANDEZ, K.; FERNANDEZ-LAFUENTE, R. Control of protein immobilization: coupling 
immobilization and site-directed mutagenesis to improve biocatalyst or biosensor performance. Enzyme Microb. Tech., v. 48, p. 107-122, 2011. ${ }^{\text {a }}$

HERNANDEZ, K.; FERNANDEZ-LAFUENTE, R. Lipase B from Candida antarctica immobilized on octadecyl Sepabeads: A very stable biocatalyst in the presence of hydrogen peroxide. Proc. Bioch., v. 46, p. 873-878, 2011. ${ }^{\text {b }}$

HUANG, S. H.; LIAO, M. H.; CHEN, D. H. Fast and efficient recovery of lipase by polyacrylic acid-coated magnetic nano-adsorbent with high activity retention. Separat. Purif. Technol., v. 51, p. 113-117, 2006.

ITABAIANA JR, I.; GONÇALVES, K. M.; CORDEIRO, Y. M. L.; ZOUMPANIOTI, M., LEAL, I. C. R.; MIRANDA, L.; XENAKIS, A. Kinetics and mechanism of lipase catalyzed monoacylglycerols synthesis. J. Mol. Catal. B: Enzym., v. 96, p. 34-39, 2013.

DE MATTOS, I. L., SHIRAISHI, K. A., BRAZ, A. D., FERNANDES, J. R. Peróxido de hidrogênio: importância e determinação. Quim. Nova., v. 26, p. 373-380, 2003.

MIYAZAWA, T.; YAMAMOTO, M.; DANJO, H. Chemoselective acylation of (hydroxyalkyl) phenols catalyzed by Candida antarctica lipase B. Biotechn. Let., v. 35, p. 625-630, 2013.

PAROUL, N.; BIASI, A.; ROVANI, A. C.; PRIGOL, C.; DALlAGO, R.; TREICHEL, H.; OLIVEIRA, D. Enzymatic production of linalool esters in organic and solvent-free system. Biop. Bios. Eng., v. 33, p. 583-589, 2010.

PAROUL, N.; GRZEGOZESKI, L. P.; CHIARADIA, V.; TREICHEL, H.; CANSIAN, R. L.; OLIVEIRA, J. V.; OLIVEIRA, D. Solvent-free geranyloleate production by enzymatic esterification. Biop. Bios. Eng., v. 34, p. 323-329, 2011.

RODRIGUES R. C.; FERNANDEZ-LAFUENTE R. Lipase from Rhizomисor miehei as a biocatalyst in fats and oils modification. J. Mol Catal B Enzym., v. 66, p. 15-32, 2010. ${ }^{\text {a }}$

RODRIGUES R. C.; FERNANDEZ-LAFUENTE R. Lipase from Rhizomисor miehei as a industrial biocatalyst in chemical process. J Mol Catal B Enzym., v. 64, p.1-22, 2010. b

SEVERIANO, A. F. J. Chemo-enzymatic epoxidation of rapeseed methyl esters: Parameters influencing the reaction and enzyme stability. Dissertação de Mestrado em Engenharia Biologica, 2008.

SILVA, M. F.; RIGO, D.; MOSSIA, V.; DALLAGO, R. M.; HENRICK, P; KUHNA, G. O.; DE, ROSA, D. C.; OLIVEIRA, D.; OLIVEIRA, J. V.; TREICHEL, H. Evaluation of enzymatic activity of commercial inulinase from Aspergillus niger immobilized in polyurethane foam. Food Biop. Process., v. 91, p. 54-59, 2013. 
TORRES, M.; ARENDS, I. W. C. E.; MAYORAL, J. A.; PIRES, E.; JEMENEZ-OSES, G.; A highly efficient, green and recoverable catalytic system for the epoxidation of fatty esters and biodiesel with $\mathrm{H}_{2} \mathrm{O}_{2}$. Appl. Catal. A.Gen., v. 425, p. 91- 96, 2012.

TZIALlA, A. A.; PAVLIDIS, I. V.; FELICISSIMO, M. P.; RUDOLF, P.; GOURNIS, D.; STAMATIS, H. Lipase immobilization on smectite nanoclays: characterization and application to the epoxidation of pinene. Bioresour. Technol., v.101, p. 1587-1594, 2010. 